\title{
Infância nada iludida: o que dizem as crianças sobre os comportamentos e riscos on-line ${ }^{1}$
}

\author{
Infancia no engañada: lo que dicen los niños sobre los \\ comportamientos y riesgos en línea
}

\section{Childhood not deluded: what children say about online behaviors and risks}

\author{
Mayra Fernanda Ferreira ${ }^{2}$ \\ Universidade Estadual Paulista (Brasil) \\ mayraunesp@yahoo.com.br
}

Fecha de recepción: 19 de agosto de 2019

Fecha de recepción evaluador: 21 de agosto de 2019

Fecha de recepción corrección: 31 de agosto de 2019

\footnotetext{
1 Este texto apresenta estudos e resultados presentes na tese "Infância (n)ativa: potencialidades de participação e cidadania às crianças na mídia digital", defendida em agosto de 2018 junto ao Programa de Pós-Graduação em Comunicação da Unesp, em agosto de 2018.

2 Mayra Fernanda Ferreira. Doutora e Mestre em Comunicação pelo Programa de Pós-Graduação em Comunicação da Unesp Bauru. Vice-coordenadora do Intercom Junior/ Comunicação Multimídia. Membro do Grupo de Pesquisa CNPq - Comunicação, Mídia e Sociedade. Jornalista da TV Universitária Unesp. https://orcid.org/0000-0003-1942-9483
} 


\title{
Resumo
}

Este estudo abre espaço à reflexão sobre a relação das crianças com a mídia digital a partir do diálogo infantil acerca dos usos, atividades e segurança que vivenciam on-line. Considerando os conceitos e os debates sobre a infância nativa digital, por meio da interlocução com 20 sujeitos infantis de nove a 11 anos em quatro grupos focais, são elucidadas as opiniões das crianças sobre o comportamento de estarem conectadas, interagindo em rede, e sobre as situações vivenciadas on e off-line que põem em xeque questões relacionadas à segurança. A partir dos dizeres infantis, confirma-se sua conexão à mídia digital, com autonomia e certa dependência, destacando positivamente as atividades que são realizadas por estarem conectadas. Por outro lado, a criticidade infantil demonstra que estão atentas aos riscos a que podem estar sujeitas em rede e que concordam com mecanismos de controle e vigilância, em especial pela família e pela escola, para se protegerem on-line. Essa avaliação das crianças elucida os aspectos positivos e negativos para uma geração digital e demonstra que há espaço para as opiniões infantis, em especial sobre temas presentes em seu cotidiano.

Palavras-chave: Infância. Mídia Digital. Atividades on-line. Segurança on-line. Opinião infantil.

\section{Resumen}

Esta investigación abre espacio para la reflexión sobre la relación de los niños con los medios digitales a través del diálogo de los niños sobre los usos, actividades y seguridad en línea. Considerando los conceptos y debates sobre la infancia nativa digital, 20 niños de 9 a 11 años en cuatro grupos focales participan con sus opiniones sobre el comportamiento de estar conectado, interactuar en una red y sobre situaciones experimentadas en línea y fuera de línea que generan dudas sobre seguridad. A partir de las palabras de los niños, se confirma su conexión con los medios digitales, con autonomía y cierta dependencia, destacando positivamente las actividades que se realizan porque están conectados. Por otro lado, las críticas de los niños muestran que son conscientes de los riesgos a los que pueden estar sujetos em línea y que están de acuerdo con los mecanismos de control y vigilancia, especialmente por parte de la familia y la escuela, para protegerse. Esta evaluación de los niños arroja luz sobre los aspectos positivos y negativos de una generación digital y demuestra que hay espacio para las opiniones de los niños, especialmente sobre temas de la vida diaria.

Palabras clave: Infancia. Medios digitales. Actividades en línea. Seguridad en línea. La opinión de los niños.

\begin{abstract}
This study opens space for reflection on the relationship of children with digital media through children's dialogue about the uses, activities and safety they experience online. Considering the concepts and debates about digital native childhood, 20 children from 9 to 11 years old in four focus groups participate with their opinions about the behavior of
\end{abstract}


being connected, interacting in a network, and about the situations experienced online and offline that raise questions about security. From the opinions of children, their connection to digital media is confirmed, with autonomy and some dependence, positively highlighting the activities that are performed because they are connected. On the other hand, child criticism shows that they are aware of the risks to which they may be subjected to a network and that they agree with control and surveillance mechanisms, especially by family and school, to protect themselves online. This assessment of children sheds light on both the positive and negative aspects of a digital generation and demonstrates that there is space for children's opinions, especially on themes in their daily lives.

Keywords: Childhood. Digital media. Online activities. Online security. Children's opinion.

\section{Introdução}

No contexto de uma ambiência tecnológica e midiática, Martín-Barbero (2009) defende que se vive em um ecossistema comunicativo, materializado pela relação com as novas tecnologias e pelos graus de interatividade que possibilitam as trocas simbólicas, construindo, assim, mediações comunicativas de cultura. Desse modo, o ecossistema comunicativo, mediado pelas técnicas e tecnologias, é estratégico porque o meio digital tem envolvido os indivíduos como parte da corporeidade, sensibilidade e cognitividade (Martín-Barbero, 2015).

Orozco-Goméz (2014) destaca que, no cenário contemporâneo, a sociedade está envolta por múltiplas mediações, uma vez que as características etárias, de classe social, étnicas e gênero também interferem no processo de ressignificação dos discursos e negociações simbólicas que situam os indivíduos em novas dinâmicas culturais e comunicativas. Ao considerar uma nova configuração das audiências, alterando a passividade para a atividade criativa, o autor aponta que surgem demandas para a comunicação e seus sujeitos a fim de que estejam em conexão com as características da sociedade, da cultura e com os processos comunicativos em mediações constantes e múltiplas.

Entre esses sujeitos estão as crianças em conexão com as tecnologias digitais. De acordo com Gasser e Palfrey (2011), essa geração, entendida como os primeiros nativos digitais da história, tem os principais aspectos da vida - interações sociais, amizades, atividades cívicas - mediados pelas tecnologias digitais. Essas dinâmicas sociais que circundam o dia a dia das crianças e jovens nativos digitais relevam identidades digitas (porque é impensável falar em identidades homogêneas) que os diferencia dos jovens de décadas passadas. Tapscott (2010) elenca oito características diferenciadoras da geração, a saber: 1) Desejo e busca de liberdade, da liberdade de escolha a de expressão; 2) Gosto pelo customizar, personalizar, inclusive a mídia a que acessam; 3) Defesa de investigação e transparência aos dados que julgam relevantes; 4) Busca por integridade e abertura 
comercial para comprarem onde quiserem; 5) Desejo de entretenimento e diversão no trabalho, na educação e na vida social; 6) Necessidade de colaboração e relacionamento on-line; 7) Aptidão pela velocidade e expectativa para respostas instantâneas; e, 8) Perfil inovador nos objetos que adquirem, nas empresas onde vão trabalhar e no processo de aprendizado.

Tais características devem ser compreendidas como marca dessa geração de nativos digitais que está conectada e em atividade na rede, do entretenimento ao trabalho, do gosto à necessidade informacional, por exemplo. Embora haja uma impressão de individualidade, uma vez que estão atrás de uma máquina e um perfil digital, eles buscam a comunidade e a aprendizagem perpassa o valor da interação, em estar junto, mesmo que on-line, com outros, especialmente quando compartilham os mesmos interesses. "Para os nativos 'ser é, antes de tudo, comunicar'. E um novo modelo comunicativo porque seu conhecimento da realidade passa, em maior medida, pelos meios e menos por uma observação e por experiências diretas. (Intercom, 2010, p. 690). Pireddu (2008, p. 182) completa: "a potência criativa da imaginação e do imaginário das crianças e dos estudantes hoje passa por uma multiplicidade de media". Enquanto um desses media, a Internet

é um desses elementos que está sendo investido pelas crianças de forma criativa. Como sujeitos ativos de suas experiências, as crianças experimentam, interpretam, representam, modificam o uso que fazem parte deste instrumento que a princípio não foi pensado como parte da cultura infantil, mas que vem sendo incorporado nas suas práticas cotidianas, sobretudo no que se refere às suas atividades lúdicas. (Alcântara, 2017, p. $163)$.

Dados do Comitê Gestor da Internet no Brasil (CGI, 2018) apontam que 85\% das crianças e adolescentes de nove a 17 anos estão on-line, majoritariamente pelo celular em atividades diversas relacionadas à educação, à interação e ao lazer. Desse total, 36\% afirmam que participam de grupos para conversar sobre o que lhes interessa. Considerando, então, esse contexto comunicacional, este trabalho apresenta um estudo ativo no qual as crianças são sujeitos em comunicação, apresentando suas opiniões sobre o que fazem on-line e como identificam a questão da segurança nesse espaço digital. A partir da realização de grupos focais, com crianças de nove a 11 anos, foi possível conhecer e problematizar as atividades e os riscos on-line nos quais se encontra a infância conectada.

\section{Apontamentos sobre a comunicação e a interação on-line}

Segundo Silva (2001), a modalidade comunicacional interativa a partir das novas tecnologias informáticas representa uma mudança significativa na natureza da mensagem, no papel do emissor e no estatuto do receptor. Nesse contexto de interações, Orozco-Gómez (2014) identifica o novo papel das audiências, enquanto receptivas, produtoras, criativas ou críticas, por meio do status que assumem diante dos demais sujeitos e dos conteúdos, na dimensão do analógico ao digital, que devem também ressignificar esse papel, tornando-se sujeitos participantes e, portanto, com a possibilidade de crescer a partir das diversas formas de participação em interações 
múltiplas. $\mathrm{O}$ autor ainda afirma que o computador, enquanto tecnologia digital, traz possibilidade à comunicação e à participação, assemelhando-se ao mundo físico, ao offline.

A partir da dimensão da interatividade é preciso entender que a convergência não se dá em um único sentido, isto é, a convergência não é apenas tecnológica, mas também é convergência cultural, cognitiva, linguística, situacional e estética, que se dá não apenas na confluência dos dispositivos materiais ou tecnológicos-digitais, nem apenas a partir da emissão inicial, mas desde a recepção. (Orozco-Goméz, 2014, p. 69).

É a partir dos receptores, que assumem novos papéis como produtores e colaboradores dos conteúdos em múltiplas plataformas, que emerge a cultura da convergência, nas palavras de Jenkins (2009). Tal cultura denota um status de consumidor interativo que participa das escolhas, interage com outros consumidores que utilizam a tecnologia a seu favor, não apenas para realizar buscas sobre o que lhe interessa, mas, sobretudo, para compartilhar experiências e até criar narrativas sobre elas e fomentar uma produção coletiva.

Nessa dinâmica, são fomentadas, portanto, "novas formas de participação e colaboração" (Jenkins, 2009, p. 313), emergindo a cultura participativa. Shirky (2011) defende que os indivíduos devem utilizar as mídias, do telefone ao computador, como instrumentos da participação de modo que sua presença importe para o outro, que o que tem a dizer seja ouvido e possa agregar ao outro. Já os usos da mídia digital, por meio de uma cultura participativa, indicam quatro caminhos: circular informações, colaborar na produção e compartilhamento de informações, criar produtos e fazê-los circular e conectar comunidades, em especial de interesses comuns (Allen, Kahne \& Middaugh, 2014).

Essa potencialidade é carregada de otimismo vislumbrando as oportunidades que a Internet traz à conexão e à cultura compartilhada e como as pessoas devem transformar suas capacidades e habilidades nas mídias em oportunidades. Como contraponto a uma visão otimista sobre as mediações tecnológicas, Belloni (2009) demonstra uma preocupação com um certo narcisismo egocêntrico devido ao comportamento social nos espaços públicos de utilização de dispositivos móveis. Complementa Bauman (2016) ao ressaltar o potencial que elas têm de serem uma armadilha, ao conectar apenas em zonas de conforto, reforçando individualidades e não criando espaços de diálogo, nos quais a controvérsia se faça necessária e as diferentes comunidades possam, de fato, dialogar. Vizer (2011, p. 239) acrescenta ao dizer que: "[as tecnologias digitais] são sumamente valiosas e específicas para estabelecer redes e formas de participação social em novas modalidades - ou no seu defeito de gerar novas formas de diferenciação e isolamento social".

Embora os autores assumam que ainda há pessoas em uma relação de passividade com o que a mídia oferece, as habilidades têm se avolumado a fim de que a produção seja compartilhada e fomente discussão, debate e interpretação coletiva. Retomando a visão determinista acerca da tecnologia, Rushkoff (1999, p. 100) questiona que "quando o mundo já não oferece um sistema social viável, a tecnologia assume”. Os sujeitos, por 
meio da interatividade, segundo o autor, desenvolvem seu potencial de participação, utilizam as informações a que têm acesso para criar, tornando-se, assim, produtores e receptores em suas mediações com as mídias.

Em meio às potencialidades de tais mídias para os sujeitos comunicantes, é importante reconhecer o perfil dos mesmos, bem como seus interesses e suas formas de utilização da mídia digital. Neste trabalho, como já mencionado, o foco está nas crianças on-line, seus comportamentos e seus dizeres sobre o que lhes interessa e afeta quando estão conectadas.

\section{Crianças (n)ativas digitais}

No processo de socialização da criança, nesta sociedade na qual se fazem presentes as mídias eletrônicas, conforme sinaliza Belloni (2009, p. 70), destaca-se o "fosso tecnológico entre as gerações que subverte a relação tradicional entre o adulto que sabe e a criança que não sabe”. Alcântara (2017) aponta que a infância contemporânea se constrói no cenário de consumo tecnológico e midiático. É uma infância que chega como sujeito dos meios de comunicação (Alzate-Piedrahíta \& Goméz-Mendonza, 2014).

No entanto, Barreto (2016) pondera que não é garantia que, ao nascer em um contexto com a presença das tecnologias, os indivíduos sejam automaticamente críticos sobre o que consomem e o que sabem de fato sobre essas tecnologias. Cruz Junior (2018) concorda e apresenta uma dualidade de visões: de um lado está quem enaltece o potencial das tecnologias para prepará-los para o futuro; de outro, quem considera as tecnologias como causas para a perda de bondade e inocência infantis, levando-os à rebeldia e à erotização precoce. No primeiro grupo está o autor Tapscott (2010), defendendo uma visão determinista e idealizada frente às tecnologias e às crianças digitais, enquanto uma relação tão natural quanto o biológico e o necessário à vida que é a respiração. Enquanto Livingstone (2011, p. 12) alerta que "a criança que maneja a tela nos parece tão habilidosa que podemos concluir confortavelmente que já sabe tudo o que precisa", o que leva o segundo grupo a ter a tendência de observar, com ênfase, as consequências relativas ao contato com conteúdos que podem a submeter a riscos on-line e off-line.

No contexto, então, dessas visões em relação às potencialidades das crianças em meio digital e deste para com elas, observa-se que, no "acesso a mais informações, as quais munem crianças e adolescentes de dados para argumentar, dialogar e questionar com cada vez mais desenvoltura" (Tomaz, 2011, p. 56), observa-se uma dualidade entre as oportunidades on-line e os riscos e a segurança on-line. Estar conectado, segundo Tapscott (2010) em um discurso otimista, é a característica central do que o autor nomeia de geração digital, focando, então, nas oportunidades. Essa geração, composta de crianças e jovens que nasceram após a popularização da Internet nos anos 1990, apresenta características que denotam sua familiaridade com as tecnologias digitais, uma vez que as próprias crianças e adolescentes se declaram os experts do lar, sem precisar da 
mediação educativa dos adultos, fazendo um uso mais intensivo e multifuncional do que os adultos (Duarte, et al., 2016).

Essa apropriação infantil das oportunidades on-line tem sido tão visível que "em lugar de ações de controle sobre os jovens, pede-se que a eles seja dada cada vez mais liberdade e autonomia para realizar o que está ao alcance 'somente' deles". (Tomaz, 2011, p. 44). Rocha (2005) afirma que essa geração tem a percepção de que os usos que fazem da tecnologia são quem determina quem ela é, ou seja, conforme se usam as tecnologias, estas se modificam para atender a novos interesses e interações que surgem on ou offline. E isso caminha na direção do que caracteriza essa geração, visto que querem estar no comando da própria vida digital e esperam poder contar com um círculo de relações diante das situações que se apresentarem on-line, sem que isso signifique controle ou restrições ao uso da rede; e neste círculo estariam a família, amigos, professores, empresas e até o Estado e suas organizações de segurança.

Além dessas oportunidades, Sampaio e Máximo (2017, p. 207), ao se referirem a pesquisas europeias e em nível global sobre os usos da Internet pelas crianças, identificaram como oportunidades on-line

as aprendizagens educacionais e o letramento digital, a participação e o envolvimento cívico, a criatividade e a auto-expressão e o fortalecimento de relações sociais e identitárias. Os estudos identificaram como riscos proeminentes os seguintes: riscos sexuais (pornografia, sexting), riscos de contatos com pessoas desconhecidas, ciberbullying, exposição e abuso de informação pessoal.

Tais oportunidades já foram por ora debatidas e abrem perspectivas positivas para a atuação em rede. Porém, nem tudo são potencialidades, cabendo reconhecer os riscos on-line, que se apresentam como uma preocupação e podem acarretar o que a visão negativa aos nativos digitais já enunciou (Cruz Junior, 2018). Essas ponderações sobre riscos e oportunidades on-line indicam um caminho, um olhar para essa infância nativa digital. Entretanto, como consideramos as crianças como sujeitos comunicantes, é importante observar se elas também os reconhecem a partir dos usos que fazem da mídia digital a fim de, então, problematizar o que encontram, fazem e buscam on-line, além de destacar as mediações nesse processo.

\section{Infância em expressividade sobre o on-line}

As crianças interlocutoras deste estudo são sujeitos de nove a 11 anos, uma vez que essa é a faixa etária já elencada em pesquisas de infância e Internet (CGI, 2018) e por ser uma idade na qual as crianças conseguem se expressar livremente sem as amarras do mundo adulto e já denotam certa personalidade sobre o que as agrada (Postman, 1999; Piaget, 1967; Vigotski, 2004). São 20 estudantes de duas escolas públicas municipais de Bauru, no interior de São Paulo, selecionadas por meio da identificação com a temática da pesquisa e a autorização dos responsáveis e da coordenação escolar. Acredita-se que a interlocução com a escola possibilita um ampliação do espaço de diálogo entre elas, assim como um potencial de intervenção visto a relação preconizada entre educação e tecnologias digitais. 
Metodologicamente, optou-se pela realização do grupo focal, já que essa técnica de pesquisa possibilita "perceber os aspectos valorativos e normativos que são referência de um grupo particular" (Costa, 2014, p. 181) e "compreender práticas cotidianas, atitudes, comportamentos prevalecentes no trabalho com alguns indivíduos que compartilham traços em comum, relevantes para o estudo e investigação do problema proposto" (Lopes, 2014, p. 482). Conforme a faixa etária e o ano escolar, os sujeitos foram organizados em quatro grupos de cinco crianças a fim de que a interlocução fosse provocadora e mais intimista para que elas pudessem debater questões inerentes a sua relação com a Internet. Para o presente texto utilizaremos só três grupos por serem representativos da problemática estudada. Cada grupo teve duração aproximada de quarenta minutos e foi gravado, pois como aponta Morin (2004), as falas dos grupos focais não devem se perder e gravá-las garante um registro que funciona como extensão dos atores, ou seja, das crianças.

$\mathrm{Na}$ sistematização do grupo focal, com a mediação da pesquisadora, o foco da discussão, em um primeiro momento, voltou-se para conhecer o que essas crianças fazem on-line para, posteriormente, debater o que encontram on-line. Por isso, as falas das crianças foram categorizadas em dois itens: 1) atividades on-line, e 2) Segurança on-line. Desse modo, são apresentados os resultados dos grupos individualmente e por temática, apresentando, inclusive, trechos literais das falas das crianças, identificas como S1 a S15. Por fim, faz-se uma síntese de cada categoria, e os resultados são problematizadas para chegar a conclusões.

\section{Atividades on-line das crianças}

Neste primeiro item, estão contempladas as questões relativas ao uso da mídia digital pelas crianças e se elas identificam as oportunidades à disposição.

Para o Grupo 1, o acesso à Internet é realizado para: Eu uso para jogar e também para fazer trabalhos (S1); Eu mais assisto vídeo no YouTube e depois, de vez em quando eu instalo aplicativos interativos e jogos (S2); Eu vejo vídeos no YouTube (S4). No canal de vídeos, além dos gameplays, os YouTubers fazem sucesso entre os sujeitos: Vish, muito (todos); Nossa, a lista é gigante (S1).

No caso de usos e atividades, S3 havia afirmado no início do grupo que usava pouco o celular e o computador e que meu negócio é mais TV mesmo. Porém, quando o assunto foram os YouTubers, S3 disse que costuma acessar os vídeos pelo celular próprio. Observa-se, nesse ponto, uma contradição que reside no uso constante versus a utilidade do uso conforme o interesse da própria criança ou do grupo ao qual faz parte.

Outra atividade pontuada é o uso do celular na escola. S1 acredita que esse uso podia existir para ajudar em trabalhos, pesquisas até mesmo nos intervalos, enquanto S3 afirma que deve ser permitido apenas na hora do intervalo porque os alunos deixarão de perguntar dúvidas aos professores e vão buscar respostas apenas na Internet. 
Neste primeiro grupo, fica nítido que as atividades elencadas correspondem ao que é mais citado pelas crianças. Destaca-se, entretanto, S1 que já tem um site próprio e um canal no YouTube em que publica assuntos do seu interesse, atuando como produtora de conteúdos, com a presença, de perto, da mãe ao dividirem o mesmo dispositivo. É perceptível também que esses sujeitos estabelecem uma relação de propriedade com os dispositivos e o desejo de querer um próprio para fazerem o que gostam. Entre os gostos, prevalecem o lazer e a identificação com "personalidades", embora os YouTubers citados não sejam crianças, e sim jovens, dos quais gostam de ouvir e ver os conteúdos publicados.

No grupo 2, os sujeitos, em especial S6 e S7, afirmam que não consigo ficar sem Internet porque querem se informar sobre tudo e também assistir a vídeos. S8 apresenta como atividade principal de seu acesso aos jogos e que a pior coisa que eu gosto de fazer na Internet é fazer tarefa. A dependência de S6 é vista na resposta: eu entro direto, em tudo, mesmo que eu tô na escola. Já S7 diz que pode ser viciada. S8 completa: eu falei que eu fico só uma hora, mas é mais de cinco. [...] Se eu pudesse, eu mexia até de noite. O uso na escola é feito por S6, como afirmou, mas S7 também acha que pode ser positivo. Com o uso da Internet, S7 acredita que você pode ter conhecimento também, não só ficar em jogos, mas também conhecer um pouquinho mais.

Sobre os dispositivos utilizados, S10 afirmou que utiliza bastante os dois, mas que está sem nenhum no momento porque está de castigo, então está se dedicando às aulas de inglês. O celular aparece com destaque para os outros sujeitos, que até dizem utilizar o dos pais se o deles quebrar. S6 completa ao dizer que eu acho que o computador é melhor pra pesquisar e o celular é melhor para assistir vídeos, jogos, essas coisas.

Os vídeos dados como exemplos são de YouTubers, como o grupo 1 exemplificou, e S8 afirmou que também tem um canal de vídeos sobre gamers, embora tenha perdido a senha recentemente. Como eles são conectados, eles sabem procurar o que gostam e isso aparece tão logo se conectam. S9 faz uma ressalva: eu tento umas dez vezes, passou de dez, eu desisto. Para escolher o que gosta on-line, S9 acha que a partir dos 8 anos as crianças já sabem fazer boas escolhas, enquanto S7 acha que a partir dos 7 anos já é possível.

Os sujeitos S6, S7 e S9 estão presentes nas redes sociais digitais: Facebook, Instagram, Whatsapp. S6 diz que minha sobrinha tem 4 anos e já mexe no whatsapp. Minha mãe não deixava eu mexer antes. Ele afirmou que fez o perfil no Facebook aos 6 anos. S7 diz que tem desde os 4 anos. Embora não tenha outras redes, S8 tem Facebook desde os oito anos.

Nesta categoria, no grupo 2, percebe-se que há uma noção da dependência diária para a utilização da Internet, assumindo que, na idade deles, eles já sabem como usá-la, em especial em redes sociais digitais nas quais estão presentes desde a primeira infância. Um dos sujeitos (S8) também tem um canal no YouTube que é seguido por alguns colegas. E a posse de dispositivos é valorativa, inclusive sendo retirada pelos pais em caso de 
desobediência, ou até substituída por outras atividades off-line, assim como na utilização dos celulares dos pais na ausência de um próprio.

O acesso do grupo 3 à Internet é realizado pelos dois dispositivos: meu acesso pela Internet é bem fácil, eu entro pelo celular, pelo computador. Como na casa da minha avó também tem Internet, eu costumo ficar lá (S15). O uso da Internet pelo celular, nesse grupo, é tão constante que é ressaltado como dependência: a gente não vive sem celular (S14) e não sei como estou vivendo sem celular, eu estou pegando o da minha mãe e ficando a tarde toda com ele (S12).

Os sujeitos assumiram ter perfil no Facebook, embora S11 e S15 não o utilizem com muita frequência, enquanto S13 já está na sua terceira conta na rede social. S13, assim como S12, possui contas em quase todas as redes: Snapchat, Instagram, Twitter, Whatsapp, Facebook. Embora administrem as contas, é perceptível um certo discernimento entre as características da rede, como demonstrado no comentário sobre o Instagram: é que eu acho muita coisa. Eu também não gosto muito de entrar porque lá tem muita coisa para você ficar olhando, mexendo (S13).

Um fato curioso é que os sujeitos usam a Internet para agendar atividades off-line: eu entro todo dia, no começo do ano a gente conversa, combina de andar de bicicleta, essas coisas (S14). E nos grupos da classe escolar, há uso quase 24 h por dia, sendo duas contas: uma para compartilhar conteúdos escolares e outra pra conversas. A gente consegue se comunicar por lá, passa matéria pra quem faltou, é bem básico (S15) e $A$ gente fala "sora, a gente vai tirar foto do livro", ai a gente tira foto de tudo e já mandou no grupo pra quem não pegou (S12). Esse uso da rede mostra a coletividade presente para além do on-line.

Como estão conectados, os sujeitos acham que eles têm a percepção de fazer um uso correto da rede. No entanto, alertam sobre o uso por outras gerações: até criança de menos de um ano já sabe mexer na Internet (S12), o meu irmão tem dois e fica lá vendo vídeo no YouTube (S15) e minha prima, ela tem um aninho e não sai do celular (S12). E $\mathrm{S} 15$ também diz que é necessário cuidado porque hoje em dia é uma época que é muito dificil de se conviver, porque muitas pessoas não saem na rua. Minha mãe mesmo não deixa eu sair muito, porque, você sabe, tem raptores e essas coisas. E a gente tem que saber como que usar isso. Nesse processo para aprender, a autonomia é ressaltada porque eu aprendi sozinha.

O papel da escola para esse uso também é mencionado porque hoje em dia todo mundo usa Internet (S11). No entanto, eles balizam que é importante o saber usar em meio às restrições da escola. Um exemplo citado pelo grupo é de que utilizam a sala de informática para trabalhos escolares, porém alguns alunos conseguem trocar a senha da Internet e divulgam para os demais colegas, assim se faz um uso inapropriado para jogos e assistir a vídeos enquanto se tem tarefa para fazer. S13 diz que a escola poderia liberar o uso no intervalo, assim ninguém ia pegar a senha da informática ou da biblioteca. Mas S14 discorda: o intervalo é uma coisa para descansar, né, vai ficar todo mundo no celular, não vai ter graça. Esse comentário mostra a importância que se dá a socialização 
em ambiente escolar e também familiar: antigamente os pais brigavam para os filhos entrarem dentro de casa, hoje em dia os pais brigam para os filhos saírem de casa (S12).

O uso constante da Internet é justificado por eles devido ao avanço da tecnologia (S14), porque cada vez mais vai trazendo mais tecnologia, jogos novos, sites novos, cada vez mais viciante (S13) e a gente tá no século XXI, isso é o celular, tipo de gente (S15). Para além do vício, percebe-se como dispositivos devem ser parte dessa geração. Na comparação entre os meios de comunicação a que têm acesso, os sujeitos indicam a superioridade da Internet. S13 e S15 destacam o YouTube frente à TV: no YouTube você assiste o que quer, tem mais opções. Tem mais conteúdos (S13). E S12 completa: Os DVDs tão perdendo, agora você só pesquisa na Internet.

Dentre as atividades positivas em rede, os sujeitos ressaltam a questão da comunicação para estar conectado com os familiares e também com amigos por meio de grupos: ninguém fica de boca fechada lá no grupo não (S13). Além disso, as amizades virtuais também são vistas como potencial da Internet, até mesmo na ponderação de S11: tem esse lance de tomar cuidado com quem você conhece, mas você também pode conhecer algumas pessoas muito importantes. Tem vezes que dão certo amizade virtual. $\mathrm{S} 13$ concorda e diz que tem dois amigos pelo Whatsapp e que se conheceram pela rede social e por gostarem do mesmo tipo de jogos. S14 também exemplifica com uma amizade virtual por conta de jogos em comum. S12 e S11 contam que têm amigos até de outros estados com quem se comunicam pela Internet.

Outro aspecto positivo da Internet é a informação e o estudo pela Internet. Tipo informação que usa para alertar, informação do mundo (S13), na internet eu costumo pesquisar esse tipo de informação, informação geral e informação escolar (S11). E, também a diversão, lá no grupo a gente se diverte até demais (S12).

Este grupo 3 tem uma presença em rede, em especial para a comunicabilidade em redes sociais digitais, bem como em grupos com diferentes finalidades. Os sujeitos sabem diferenciar esses usos e aspectos positivos e negativos da utilização constante da Internet e como ela pode ser útil para a comunicação, o acesso a informações e à educação. Embora estejam conectados, também ressaltam como o off-line é importante, em especial no ambiente escolar e na convivência familiar e entre amigos, destacando, na contramão, que a Internet pode aproximar por afinidades mesmo quando não há presença física.

\section{Segurança on-line para as crianças}

A segunda categoria de análise dos grupos focais se refere à segurança on-line e aos riscos aos quais as crianças podem estar submetidas em suas atividades on-line. Além disso, versa sobre o controle e a orientação para estarem on-line, bem como o papel de pais, responsáveis, educadores.

O primeiro grupo, ao falar dos dispositivos que não funcionam mais, demonstrou uma preocupação com o que se publica pelo celular. S2 até exemplificou: porque na Internet [...] se você coloca "As meninas do $5^{\circ}$ ano A tão fazendo bagunça", aí eles vão 
lá e vão acreditar e a gente pode tá quieto. S1, ao comentar da sua conexão diária no YouTube, conta que vejo umas coisas estranhas [...] e eu tento denunciar só que eles não têm essa opção no celular, ai eu tenho que abrir no computador e procurar [o vídeo para denunciar].

Os demais sujeitos concordam que há vídeos inapropriados, com conteúdos ruins para eles, e que costumam denunciar ao YouTube quando possível porque há a dificuldade de não conseguirem fazer pelo celular. S4 complementou: eu entrei no YouTube, eu não pus no vídeo, mas tava escrito assim "Anitta faz pacto com o capeta", aí eu não coloquei no vídeo. Eu tentei denunciar, mas não consegui. Não tem essa opção no celular.

Além de identificarem esses conteúdos, os sujeitos assumem que há um controle dos pais e que isso é positivo, tanto que muitos têm até a senha do celular: quando eu tinha o meu celular ele [o pai], três, quatro vezes na semana ele via o meu celular (S2); meu pai só vigia o Facebook e aí o YouTube, que eu tenho uma conta lá no Google, fica ali e aí, às vezes minha mãe entra pra ouvir as músicas dela, [...] aí eu tenho que ensinar ela ver no histórico também. Essa fala demonstra o julgamento positivo ao controle tanto que ensinam os pais uma forma dele, como observar os sites navegados no histórico.

Dentre outros riscos, S3 alerta: a gente tem que tomar cuidado pra colocar os nossos dados em aplicativos que a gente não sabe. [Os hackers] podem roubar nossas dados. E S1 exemplifica: eu uso muito o computador da minha mãe e ele tem webcam, aí meu pai sempre fala pra tirar a webcam de on-line, porque tem pessoas hackers que eles podem entrar e nos ver.

S2 também traz um exemplo: têm crianças que, por exemplo, vamos supor, ela conversa com um monte de estranhos que ela não conhece. Eu tenho uma amiga e o irmão dela falou: "Nossa, você tem muita pouca pessoa no seu Facebook..." Aí, tipo assim, ela começou a adicionar um monte de gente que ela não conhecia, e outro dia, faz bastante tempo que ela falou assim pra mim e pra minha prima: "Nossa, esses dias uma mulher lá, do nada, no meu Facebook e falou assim: 'Oi amiguinha' e com um monte de arminha”, sabe? Aí a minha amiga, minha prima, pegou e falou assim: "Vai, idiota, quem mandou você ficar adicionando um monte de gente que você não conhece".

Essas situações socializadas pelos sujeitos indicam que eles se preocupam com o que fazem on-line e como estão expostos, julgando necessário o controle, até mesmo retomando a escola enquanto um lugar onde o celular não deve ser utilizado sem limites para evitar esses riscos porque eles acham que precisam de orientação sobre o que é feito na Internet.

No caso do grupo 2, assim como já assinalamos alguns sujeitos se assumem como viciados na Internet e sabem que isso é perigoso: eu sou viciada, mas meu pai pegou o meu celular, agora eu tô me controlando (S6). Enquanto riscos, S8 diz o de ser hackeado e S6 se preocupa com o fato de adicionar pessoas, vamos dizer que algum explorador de crianças, ele se passa por algum amigo nosso, pela mãe, por algum familiar. Tem que 
tomar bastante cuidado. S10 opina: se você adiciona uma pessoa é só você ir lá e excluir. S8 também discorda dessa preocupação e assume pra si: é só não começar a conversar com ele. Eu ignoro.

S8 também diz que os pais não controlam o que ele faz on-line e os demais sujeitos falam que ele se acha muito esperto. S6 diz que minha mãe é um hacker, hackeia Facebook, Whatsapp, hackeia tudo. Entra em todas as conversas. S7 e S8 dizem que ensinam os pais a ver o que eles fizeram on-line. Mas quando tem alguma coisa estranha eu mostro pra ela (S7). E S6 exemplifica: eu tinha criado uma página no Facebook, aí o menino, mandou assim, "oi moça você tem namorado", "mãe olha isso daqui", aí ela, eu nem respondi nada e saí. S8 diz que os pais perguntam a ele sobre algumas conversas que leem, e S7 completa: Nossa, acontece isso comigo também. Minha mãe vê as conversas e fala "o que é isso?", ai eu sempre conto.

Sobre essa atitude dos pais, os sujeitos julgam correto porque eles só querem proteger (S7) e sabem que as crianças precisam dessa proteção, citando um caso de um colega de turma que faz cada coisa (S6) e fala cada coisa pra gente, horrorosa, nem vou comentar aqui porque senão vou ter que botar "piii". Acho que não tem nenhum responsável cuidando da Internet dele (S7) ou ele apaga as conversas, só se for (S6). Segundo os sujeitos, não há necessidade de outro tipo de proteção além dos pais, embora alguns professores fiquem atentos: minha professora de Educação Física ia comentar com a minha mãe que eu tava ficando até tarde na Internet, no Facebook, que ela entrou e eu tava 2 h da manhã no Facebook (S7). E os sujeitos também encontram alternativa de burlar os pais: eu espero meus pais dormirem, pego o meu celular, coloco o fone e vejo vídeos no YouTube (S8). Além de questionarem: às vezes os adultos proíbem as crianças de usar a Internet. Ah, não sei porquê.

Os sujeitos também dizem que têm assuntos que não são legais para crianças: não é legal para uma criança de 5 anos ver vídeo de palhaço assassino. Você vai ter trauma de palhaço (S9) e várias crianças estão assistindo vídeo da "Peppa" e aparecem vários vídeos da "Peppa" que a criança vai querer ver e vai fazer e vai acabar se machucando".

Esse grupo 2 apresenta exemplos de situações de riscos às crianças on-line e demonstram uma visão crítica sobre as mesmas, indicando que os pais devem observar o que os filhos fazem on-line, e até mesmo falam on-line. Também sabem que o comportamento de estar on-line, mesmo quando os pais não sabem, é equivocado, mas como não conseguem ficar sem Internet não há outra alternativa. Reconhece-se que há liberdades para o uso, mas há observação dos pais, mais que restrições, e o controle aparece como castigo, o ficar sem o celular no caso de S7 e S10.

Já no grupo 3, no quesito segurança e riscos on-line, os sujeitos demonstram uma preocupação com o saber utilizar a rede. S14 pondera que é importante saber usar, 
relembrando os casos do jogo "Baleia Azul"'. S13 diz que tem gente que usa a Internet pra passar trote também. No caso de conversas pela rede, eles ressaltam que só conversam com quem conhecem e até bloqueiam as pessoas desconhecidas. S15 fala do risco de, ao perguntar quem é a pessoa, já ter os dados roubados. Outros riscos exemplificados são de ameaça, já presenciada por S12, e pedofilia, apontada por S11 que também destaca que é importante que as crianças tenham informação sobre isso. S13 completa dizendo que deveria ter campanhas e S12 sugere um site como o Facebook para divulgar essas informações.

Além desse suporte informacional, os sujeitos dizem que os pais acompanham o que eles fazem on-line: ela vê com que eu tô conversando e fala "eu não quero você conversando com essa tal pessoa" (S12) e minha mãe quando eu comecei a mexer no celular ela olhava bastante, agora ela parou um pouco, ela já sabe que eu sei mexer (S13). Essa fala denota que os pais reconhecem as competências adquiridas pelos filhos no uso da Internet e também lhes asseguram a autonomia de fato.

Ao falar do uso constante da Internet, os sujeitos ponderam a questão do vício, afirmando que há jogos e conteúdos bons e ruins: aí o cara tinha que matar o oponente, se ele não matasse, você ia ficar alguns segundos sendo enforcado. Aí um menininho morreu. Uns meninos de 12 anos por causa desse jogo. Ele fazia todo dia. Ele não saia da casa dele (S13). Esse domínio que julgam ter da Internet também é perigoso, como menciona S15: hoje em dia qualquer um pode ter controle de um computador, se souber hackear. E o discernimento vai ocorrer só por volta dos 11 anos, na opinião dos sujeitos. Cabe ressaltar que essa é faixa etária na qual se encontram e julgam que o risco antes disso é mil vezes maior (S12), sendo o controle dos pais fundamental: Quando eu era mais novo, minha mãe fazia duas horas de estudo, duas horas pra mim se divertir e 2 horas se eu quisesse mexer na Internet (S12).

O fato de estarem conectados em grupos em redes sociais também gera um alerta, a partir de um episódio vivenciado pelo grupo: tem um grupo que a gente criou do NER todo mundo. Entrou um senhor, não sei da onde [...] Esse senhor, ele era pedófilo (S12). Ao perceberem isso, porque o senhor havia enviado mensagem privada a uma menina da turma, muitos saíram do grupo. Meu pai foi ligar eu celular, ele viu esse grupo e ele ficou muito revoltado da vida. "O que você está falando nesse grupo aqui? Tinha pornografia lá” [...] Ai ele falou que eu não entro em nenhum grupo sem a permissão dele. A não ser que seja gente que eu conheço que tem que mostrar para ele, porque senão...

A partir de experiências dos próprios sujeitos do grupo 3, eles demonstram uma preocupação para obter segurança on-line, identificando riscos e até propondo situações para que as crianças não estejam tão submetidas a eles. O papel da família e também a divulgação de informações, que podemos considerar uma função de mídias, tornam-se

\footnotetext{
3 O jogo "Baleia Azul" se tornou notícia no Brasil em abril de 2017, após a morte de uma adolescente, supostamente devido aos desafios, inclusive contra a própria vida, que o jogo impunha aos jogadores pelas redes sociais digitais.
} 
essenciais para assegurar maior segurança, ao mesmo tempo em que acreditam que as próprias crianças têm autonomia e competência de discernimento perante os riscos.

\section{Indicativos sobre as opiniões infantis}

A síntese dos grupos acerca das atividades on-line ratifica o acesso diário à Internet, em especial pelo celular, confirmando os dados de CGI (2018). A utilização, por meio de perfis próprios, de redes sociais digitais é ressaltado pelas crianças, assim como os jogos e as pesquisas on-line que auxiliam em oportunidades de lazer e de educação. Para Passarelli, Junqueira e Angeluci (2014, p. 174), "para os jovens contemporâneos prevalece um borramento das fronteiras entre suas atividades de entretenimento, comunicação, estudo, trabalho e relacionamentos familiar e social". Essa constatação dos autores se reflete no posicionamento das crianças, uma vez que as atividades elencadas têm a mesma valoração, além do fato de atividades de pesquisa são realizadas para fins escolares e demais curiosidades do universo infantil. Dentre as plataformas acessadas, o YouTube recebeu menções em todos os grupos, sendo utilizado para diversão e acesso a informações, em especial sobre temas de interesse e que são publicados majoritariamente por YouTubers.

Ao destacar as potencialidades de comunicação, interação e aprendizagem, as crianças, nos respectivos grupos, consideram a mídia digital positiva para elas, bem como para as demais faixas etárias. Elas também ressaltam que dominam tal mídia e conseguem acessar conteúdos que lhes são interessantes. Paralelamente também reconhecem os riscos on-line a que estão submetidos. Tais riscos se apresentam às crianças no que concerne à privacidade, ao acesso a conteúdos impróprios a eles, também no julgamento dos sujeitos, e à dependência. "Se considerarmos que eles estão cada dia mais conectados, ao ponto de reconhecerem o risco de ficarem viciados nessa forma de vida conectada, tais questões tornam-se ainda mais relevantes, pois é nessas interações que eles estão construindo seus referenciais de leitura e participação no mundo" (Sampaio \& Máximo, 2017, p. 213). Na questão da leitura, muitos sujeitos indicam o acesso a informações inverídicas que podem ser prejudiciais a crianças, assim como a conteúdos de suicídio e de pedofilia que os expõem a situações do on ao off-line, em especial por meio do contato com pessoas desconhecidas com as quais podem se relacionar on-line e isso repercutir no off-line.

Ao mesmo tempo, as crianças indicam que é necessário saber utilizar a rede e que precisam da confiança dos pais para tanto, mesmo julgando necessário que estes controlem os usos e saibam o que estão fazendo on-line. Os sujeitos também sugerem que haja campanhas e socialização de informações de alerta acerca desses riscos e que à escola também cabe esse papel de orientação sobre como usar a rede. Essa dimensão de segurança e insegurança on-line, assim como do controle e da vigilância, é de conhecimento das crianças, o que é positivo, mas, ao mesmo tempo, gera alertas sobre situações vivenciadas por elas e que não encontram formas institucionais da rede nem de políticas públicas que se direcionem a como proteger as crianças on-line, sem que isso ressoe em perda de autonomia a elas. 


\section{Conclusões}

Os resultados aqui apresentados demonstram que a Internet se apresenta aos sujeitos de modo positivo e também negativo. Ao comentarem sobre os acessos e os usos, eles reconhecem as potencialidades, talvez sem nomeá-las como oportunidades de um "mundo" que se abre às informações e às interações e que podem repercutir no off-line. A comunicação entre os pares é a mais valorizada pelos sujeitos que criam redes e comunidades para trocas de informações de interesses comuns, como o são os conteúdos escolares. Do mesmo modo, reconhecem que há espaço para consumo de informações, principalmente com foco em pesquisas, e para atividades de lazer. No entanto, não foi mencionado o potencial cívico e participativo enquanto oportunidades on-line, como nos colocam autores da geração conectada. Tais oportunidades aparecem de modo subtendido quando as crianças reconhecem que a Internet é um espaço para emitirem opiniões e produzir conteúdos sobre o que lhes interessa, inclusive porque entre os sujeitos temos dois que possuem um canal próprio no YouTube.

Além desses usos potenciais da rede, os resultados de ouvir as crianças sobre sua vida on-line repercutem em compreender sua atuação off-line e identificar como a mediação da mídia digital não é exclusivamente sua fonte de interações e expectativas. Tal aspecto fica nítido quando o grupo 3 menciona o grupo que a turma escolar possui para socialização de informações relativas ao cotidiano da sala de aula, ao mesmo tempo em que fazem distinção entre tal compartilhamento com outros assuntos também pertinentes à turma que é foco de outro grupo on-line.

Outra dimensão dessa interface on e off-line, dá-se na menção a espaços públicos para a vivência infantil em contraponto com a dependência que assumem ter em relação a estarem conectados diariamente, em especial pelo celular que garante a portabilidade e ubiquidade, acompanhando os sujeitos em todos os espaços, inclusive no ambiente escolar, mesmo diante da proibição de utilizar os dispositivos pela coordenação pedagógica. Os sujeitos demonstram o interesse pelo off-line, reconhecendo-o enquanto um espaço de interações e de contribuições para sua socialização, embora tenham receio dos riscos devido à insegurança das ruas, o que os leva a questionar leis que garantam a proteção às crianças.

Essa insegurança é tida como maior que a on-line, uma vez que muitos pais exercem uma presença e um controle diante do que os filhos fazem na Internet. Este controle é avaliado como necessário, inclusive com os pais tendo acesso às contas e senhas para acompanhar as conversas e os conteúdos acessados. Como as crianças têm um domínio da tecnologia digital superior a muitos dos responsáveis, eles indicam que é importante que haja outros mecanismos de proteção, como a realização de campanhas, alertas até mesmo nos próprios dispositivos e orientações na escola para que elas sejam mais conscientes acerca desses riscos e não sejam vítimas. Apesar de concordarem com essa vigilância, muitas crianças afirmaram que burlam os pais para continuarem acessando a Internet, além do tempo estipulado e das ordens para se dedicarem a outras 
tarefas. Como assumem que estão viciadas e que isto é muito ruim, elas não sabem como se desvencilhar. É provável que o sentimento de grupo os faça estar on-line para continuar como parte de uma comunidade e antenados com o que acontece nesse espaço.

Identificar, portanto, o que pensam e dizem as crianças sobre os comportamentos e os riscos on-line as coloca como protagonistas do uso da mídia digital, como se espera dessa infância nativa digital. Além disso, possibilita conhecer o que de fato elas observam ao estarem on-line, ao mesmo tempo em que vivenciam o off-line, fomentando discussões entre elas, a partir das reflexões aqui iniciadas, e os adultos que atuam como seus agentes socialização. Como a família e a escola são citadas nesses dizeres infantis, é notável que as crianças esperam também estarem em conexão com essas instituições, de modo que a experiência on-line seja com segurança, cumplicidade, compartilhamento mútuo e autonomia. É claro que as crianças sabem utilizar a mídia digital. O que elas também querem é que saibam o que pensam e como querem que os adultos com elas interajam nesse meio.

\section{Bibliografia}

Alcântara, A. (2017). O brincar em ambiente virtual: jogar, postar, conversar. In:

(Org.). Comunicação e infância: processos em perspectiva (pp. 151-173). São Paulo: Pimenta Cultural.

Allen, D., Kahne, J., \& Middaugh, E. (2014). Youth, New Media, and the Rise of Participatory Politics. Oakland: Youth and Participatory Politics Research Network, 2014. Disponível em: <https://ypp.dmlcentral.net/>.

Alzate-Piedrahíta, M., \& Gómez-Mendonza, M. La infancia contemporánea. (2014). Revista Latinoamericana de Ciencias Sociales, Niñez y juventude (12), pp. 77-89, Bogotá.

Barreto, C. (2016). Adolescentes em rede: caminhos, aprendizagens, possibilidades de cidadania. Passagens (1), pp. 99-106, Ceará.

Bauman, Z. (2016, 9 de janeiro) 'As redes sociais são uma armadilha'. Entrevista a Ricardo de Querol. EL PAÍS Brasil. Disponível em: $<$ https://brasil.elpais.com/brasil/2015/12/30/cultura/1451504427_675885.html $>$.

Belloni, M. (2009). O que é sociologia da infância. Campinas: Autores Associados. CGI. (2018). TIC Kids online Brasil 2017: Pesquisa sobre o uso da internet por crianças e adolescentes no Brasil. São Paulo: Comitê Gestor de Internet no Brasil.

Costa, M. (2014). Grupo focal. In: DUARTE, Jorge; BARROS, Antonio (Orgs). Métodos e Técnicas de Pesquisa em Comunicação. (pp. 180-192). São Paulo: Atlas. 
Cruz Junior, G. (2018). Entre filhos e órfãos da cibercultura: revisitando a noção de nativos digitais. Revista Observatório, (1) pp. 837-858, Palmas.

Duarte, G. et al. (2016). Internet seguro y relaciones interactivas en jóvenes mexicanos. Hallaszgos 2015. Comunicação \& Sociedade, (1), pp. 201-240, São Bernardo do Campo.

Ford, S., Green, J., \& Jenkins, H. (2014). Cultura da conexão: criando valor e significado por meio da mídia propagável. São Paulo: Aleph, 2014.

Gasser, U., Palfrey, J. (2011). Nascidos na era digital: entendendo a primeira geração dos nativos digitais. Porto Alegre: Artmed.

INTERCOM. (2010). Enciclopédia INTERCOM de comunicação. São Paulo: Sociedade Brasileira de Estudos Interdisciplinares da Comunicação, 2010.

Jenkins, H. (2009). Cultura da convergência: a colisão entre os velhos e novos meios de comunicação. São Paulo: Aleph, 2009.

Livingstone, S. (2011). Internet literacy: a negociação dos jovens com as novas oportunidades on-line. MATRIZes (4), pp. 11-42. São Paulo.

Lopes, B. (2014). Grupo focal na pesquisa em Ciências Sociais e Humanas. Revista Educação e Políticas em Debate (2). pp. 482- 492. Uberlândia.

Martín-Barbero, J. (2015). ¿Desde dónde pensamos la comunicación hoy?. Chasqui. (128), pp. 13-29. Quito.

Martín-Barbero, J. (2009). Uma aventura epistemológica. Entrevista a Maria Immacolata Vasallo de Lopes. Matrizes. (2). pp. 143-162. São Paulo.

Morin, A. (2004). Pesquisa-ação integral e sistêmica: uma atropedagogia renovada. Rio de Janeiro: DP\&A.

Orozco-Gómez, G. (2014). Educomunicação: recepção midiática, aprendizagens e cidadania. São Paulo: Paulinas.

Passarelli, B., Junqueira, A., \& Angeluci, A. (2014). Os nativos digitais no Brasil e seus comportamentos diante das telas. Matrizes, (1). pp. 159-178. São Paulo.

Piaget, J. (1967). Psicologia da inteligência. São Paulo: Fundo Cultural.

Pireddu, M. (2008). Do fornecimento à participação. O aprendizado entre modelos teóricos e tecnologias. In: DI FELICE, Massimo. Do público para as redes: a comunicação digital e as novas formas de participação social. pp. 175-189. São Caetano do Sul: Difusão Editora.

Potsman, N. (1999). O desaparecimento da infância. Rio de Janeiro: Graphia. 
Rocha, R. (2005). Da geração X à geração "ctrl alt del": consumindo tecnologia, reiniciando a cultura. In: LEÃO, Lucia (Org.). O chip e o caleidoscópio: reflexões sobre as novas mídias. pp. 487-494. São Paulo: Editora Senac,

Sampaio, I., Máximo, T. (2016). Literacia digital: crianças, riscos e oportunidades na internet. In: Soares, Ismar de Oliveira; Viana, Claudemir Edson, Xavier, Jurema Brasil. Educomunicação e suas áreas de intervenção: novos paradigmas para o diálogo intercultural. Pp. 206-216). São Paulo: ABPEducom.

Silva, M. (2001). Sala de aula interativa. Rio de Janeiro: Quaret.

Tapscott, D. (2010). A hora da geração digital: como os jovens que cresceram usando a internet estão mudando tudo, das empresas aos governos. Rio de Janeiro: Agir Negócios.

Tomaz, R. (2011). Da negação da infância à invenção dos tweens: imperativos de autonomia na sociedade contemporânea. Universidade Federal do Rio de Janeiro, Rio de Janeiro.

Vigotski, L. (2004). Psicologia Pedagógica. São Paulo: Martins Fontes.

Vizer, E. (2011). A trama (in)visível da vida social: comunicação, sentido e realidade. Porto Alegre: Sulina. 